Journal Of Islamic Management

Vol. 2, No. 1, Januari 2022

E-ISSN: 2774-3365

Journal hompage http://jurnalfdk.uinsby.ac.id/index.php/JIM

\title{
Fundraising dalam Lembaga Filantropi Islam
}

\author{
Usfiyatul Marfu'ah', Muhammad Aji Shadiqin ${ }^{2}$ \\ ${ }^{1,2}$ Universitas Islam Negeri Walisongo Semarang \\ 1usfiyatulmarfuah@walisongo.ac.id, ${ }^{2}$ ajishadiqin21@gmail.com
}

\begin{tabular}{l}
\hline Article Info \\
\hline Article history: \\
Received 15 Mei 2021 \\
Received : 13 Desember \\
2021 \\
Accepted : 7 Januari 2022 \\
Published : 7 Januari 2022 \\
Page : 1 - 11 \\
\hline
\end{tabular}

Keyword:

Pendistribusian, Zakat Produktif

\begin{abstract}
Surviving during a pandemic is not easy, including for philanthropic institutions. The Amil Zakat Institution is one of the Islamic philanthropic institutions that collect funds from muslims. Fundraising (collecting funds) in this pandemic period has two interrelated sides. The firdt side is not easy, because everyone is affected economically from the pandemic. On the other side, fundraising is important, to be able to help people who are most severely affected. This study discusses the methode used by philanthropic institutions in raising funds during the pandemic, through two research questions. First, what is the fundraising procedure during a pandemic. Second, how to increase the number of donors during a pandemic. Through descriptive qualitative methode, this reseaarch explore data by means of observation, interviews, and documentation. The result of the study show that first, the fundraising conducted by zakat management institutions is not much different before the pandemic, it's just that the limitation of working time and meeting other people during the pandemic creates obstacles. Thus, efforts are being made to strengthen fundraising through online. Second, increasing the number of donors during a pandemic is not an easy endeavor. Therefore, the increase in the number of donors is carried out qualitatively, by taking care of existing donors through the best service. Thus, the implications of this study indicate that the pandemic is a formidable challenge for philanthropic institutions to be able to survive abd provide maximum service to the community.
\end{abstract}

Bertahan di masa pandemi tidak mudah, termasuk bagi lembaga filantropi. Lembaga Amil Zakat merupakan salah satu lembaga filantropi Islam yang mengumpulkan dana dari ummat Islam. Fundraising (pengumpulan dana) di masa pandemi seperti sekarang ini memiliki dua sisi yang saling berakitan. Sisi pertama tidak mudah, karena semua orang terkena dampak ekonomi dari pandemi. Sedangkan sisi yang lain fundraising penting, untuk dapat membantu orang terdampak paling parah. Penelitian ini membahas tentang cara yang digunakan lembaga filantropi dalam mengumpulkan dana di masa pandemi, melalui dua pertanyaan penelitian. Pertama, bagaimana prosedur fundraising semasa pandemi, kedua bagaimana cara meningkatkan jumlah donatur di saat pandemi. Melalui metode kualitatif deskriptif, penelitian ini menggali data dengan cara observasi, wawancara, dan dokumentasi. Hasil penelitian menunjukkan bahwa pertama, fundraising yang dilakukan lembaga pengelola zakat tidak jauh berbeda dengan saat sebelum pandemi, hanya saja pembatasan waktu bekerja dan bertemu orang lain saat pandemi menjadikan kendala. Sehingga, upaya yang dilakukan dengan memperkuat fundraising melalui online. Kedua, meningkatkan jumlah donatur di saat pandemi merupakan usaha yang tidak mudah. Oleh karena itu, peningkatan jumlah donatur dilakukan secara kualitatif, dengan merawat donatur yang telah ada melalui layanan terbaik. Sehingga, implikasi dari penelitian ini menunjukkan bahwa pandemi menjadi tantangan yang berat bagi lembaga filantropi untuk dapat tetap survive dan memberikan layanan maksimal kepada masyarakat.

Copyright (C) 2022 Journal Of Islamic Management. All rights reserved.

\section{Editorial Office:}

Program Studi Manajemen Dakwah, Fakultas Dakwah dan Komunikasi, UIN Sunan Ampel Surabaya.

Jl. Ahmad Yani 117 Surabaya, Jawa Timur, Indonesia.

Email: jim@uinsby.ac.id 


\section{Pendahuluan}

Pandemi telah membawa dampak pada segala aspek kehidupan. Beberapa dampak yang paling bisa dirasakan ialah di bidang ekonomi dan kesehatan. Di bidang ekonomi, terjadi penurunan nilai ekonomi dan pendapatan masyarakat akibat penerapan beberapa aturan baru dalam masyarakat. Menurunnya pendapatan masyarakat juga dapat memengaruhi nilai penghimpunan lembaga-lembaga filantropi yang ada. Ironinya, situasi pandemi ini juga sangat terbantu dengan adanya lembaga filantropi.

Penelitian ini membahas tentang filantropi yang ada di Islam. Dalam agama Islam, terdapat ajaran berderma atas bahasa lainnya ialah zakat, infaq, dan shadaqah, serta wakaf. Meski memiliki padanan arti dan ketentuan tersendiri, keempat ajaran tersebut mengajarkan manusia tentang nilai-nilai kemanusiaan melalui berbagi. Ajaran agama inilah yang kemudian diinstitusionalisasikan melalui lembagalembaga pengelola zakat, infaq, dan shadaqah serta wakaf (ZISWAF). Secara singkat, lembaga yang mengatur tentang kedermawanan dibagi menjadi 2 ranah. Pertama, ranah pemerintah yang terinterpretasikan melalui lembaga yang bernama Badan Amil Zakat Nasional (BAZNAS), sedangkan kedua lembaga yang didirikan atas inisiatif pendirian dari masyarakat, organisasi masyarakat,

\footnotetext{
1 Marianus Mantovanny Tapung, dkk, Bantuan Sosial dan Pendidikan Kesehatan bagi Masyarakat Pesisir yang Terdampak Sosial-Ekonomi selama Patogenesis Covid-19 di Manggarai, Transformasi: Jurnal Pengabdian Masyarakat, 16 (1), 2020: 12-26; Erni Panca Kurniasih, Dampak Pandemi Covid 19 terhadap Penurunan Kesejahteraan Masyarakat Kota Pontianak, Prosiding Seminar Akademik Tahunan Ilmu Ekonomi dan Studi Pembangunan, 2020, 1-13; Ahmad Khoirudin, Analisis Dampak Pandemi Covid-19 terhadap Perekonomian Provinsi Sumatra Selatan, Jurnal Iqtishaduna: Economic Doctrine, 6 (1) 2021, 532-541; Nuryadi dan Nisa Lestari, Dampak Pandemi Covid-19 terhadap Tenaga Kerja Desa Cibanteng Kecamatan
}

lembaga masyarakat, yang telah mendapatkan ijin dari pemerintah. Untuk pola yang kedua ini dinamakan Lembaga Amil Zakat (LAZ) yang memiliki nama bermacam-macam.

Fundraising lembaga filantropi menjadi hal yang penting, terlebih di masa pandemi. Arti penting filantropi ini setidaknya menyangkut tiga hal. Pertama, realitas pandemi membuat banyak orang yang kehilangan mata pencaharian sehingga tidak menutup kemungkinan menambah data kemiskinan ${ }^{1}$. Kedua, bertambahnya data kemiskinan mengharuskan untuk semakin meningkatkan solidaritas dan kepekaan sosial agar tidak terjadi ${ }^{2}$. Ketiga, fundraising merupakan nafas bagi lembaga filantropi ${ }^{3}$.

Alasan-alasan di atas yang kemudian membuat pentingnya penelitian ini. Tujuan akhir dari penelitian difokuskan pada upaya lembaga filantropi Islam mampu survive dalam kondisi pandemi, selain itu lembaga filantropi juga diharapkan mampu mengajak masyarakat kaya untuk berbagi sebagian hartanya, meskipun tentunya tidak mudah, namun inilah tantangan yang dilakukan.

Studi tentang fundraising di lembaga filantropi di saat pandemi sudah banyak dilakukan. Akan tetapi studi-studi sebelumnya lebih banyak fokus pada peran lembaga dan dana zakat saat pandemi, misalnya studi yang dilakukan oleh Rizal

Ciampea Kabupaten Bogor, Yustisi: Jurnal Hukum \& Hukum Islam, 6 (1) 2019, 29-38.

${ }^{2}$ Imron Hadi Tamim, Filantropi dan Pembangunan, Jurnal Community Development, 1 (1), 2016, 121136

3 Risma Ayu Kinanti, dkk, Optimalisasi Fundraising Zakat pada Kerjasama Institusional Indonesia Melalui E-Commerce Pasca Pandemi Covid-19, Filantropi: Jurnal Manajemen Zakat dan Wakaf, 2 (1), 2021, 20-37; Atik Abidah, Analisis Strategi Fundraising terhadap Peningkatan Pengelolaan ZIS pada Lembaga Amil Zakat Kabupaten Ponorogo, Kodifikasia, 10 (1), 2016, 163-189 
dan Mukaromah ${ }^{4}$; Darmawan dan Desiana ; Amanda $\mathrm{dkk}^{6}$; Iskandar, Possumah, dan Aqbar ${ }^{7}$; Sakinah, dan Maulana ${ }^{8}$; Rosadi ${ }^{9}$; Harisah, $\mathrm{dkk}^{10}$; Nopiarda, dan Sandani ${ }^{11}$; dan Kadir, dkk ${ }^{12}$; serta fokus pada potensi penerimaan zakat, sebagaimana ditulis oleh Hasanah ${ }^{13}$.

Rizal dan Mukaromah ${ }^{14}$ menyoroti tentang peranan dana ZISWAF yang dijadikan sebagai jalan bagi penanggulangan kemiskinan melalui pengelolaan dana yang tidak hanya secara konsumtif saja melainkan menggunakan cara produktif juga. Pengelolaan dana ZISWAF secara konsumtif guna menanggulangi kebutuhan dasar seharihari masyarakat seperti bahan makanan, sementara pengelolaan produktif sebagai langkah preventif yang mampu meningkatkan kegiatan investasi, produktivitas, dan terkuranginya pengangguran.

Amanda $\mathrm{dkk}^{15}, \quad$ fokus pada mekanisme dan implementasi pendistribusian zakat dalam

${ }^{4}$ Fitra Rizal dan Haniatul Mukaromah, Filantropi Islam Solusi Atas Masalah Kemiskinan Akibat Pandemi Covid-19, Al Manhaj: Jurnal Hukum dan Pranata Sosial Islam, 3 (1) 2021, 35-66

5 Awang Darmawan dan Rina Desiana, Zakat dan Pemerataan Ekonomi di Masa Pandemi Covid-19, Al Azhar: Journal of Islamic Economics, 3 (1), 2021, 12-21

6 Gebrina Rizki Amanda, dkk, Pendayagunaan Zakat pada Masa Pandemi Covid-19, Jurnal Imiah Ekonomi Islam (JIEI), 7 (1), 2021, 216-222

7 Azwar Iskandar, Bayu Taufiq Possumah, dan Khaerul Aqbar, Peran Ekonomi dan Keuangan Sosial Islam Saat Pandemi Covid-19, SALAM: Jurnal Sosial \& Budaya Syar'i, 7 (7), 2020, 625-638 ${ }^{8}$ Nur Sakinah, dan AG Maulana, Peran Distribusi Harta (Zakat) sebagai Solusi Ekonomi di Saat Pandemi Covid-19 pada BAZNAS Kabupaten Kepulauan Meranti, Kutubkhanah: Jurnal Penelitian Sosial Keagamaan, 20 (1), 2020, 65-79

9 Syukri Rosadi, Peran UPZ (Unit Pengumpul Zakat) Ujungbatu dalam Meningkatkan Ekonomi Masyarakat saat Pandemi Covid-19, HUKUMAH: Jurnal Hukum Islam, 3 (2), 2020, 141-151

10 Harisah, dkk, Peran Zakat dalam Pemulihan Ekonomi saat Pandemi Covid-19, Syar'i, 4 (1), 2021, 54-66 penanggulangan pandemi. Dana zakat ikut memberikan sumbangsih pada penanganan pandemi seperti digunakan untuk sektor kesehatan, seperti pengadaan APD, mendirikan ruang isolasi, mengadakan penyemprotan disinfektan pada lingkungan, serta sosialisasi pencegahan pada masyarakat. Di sektor ekonomi, dana zakat digunakan untuk membantu pemulihan perekonomian masyarakat yang terkena dampak pandemi. Sektor ini berupa pemberian bantuan sembako, dana bantuan untuk karyawan yang terkena PHK, ustadz/ustadzah, penyuluh agama, guru ngaji, para imam masjid, cash for work, dan lainnya. Selain itu, studi lain yang dilakukan Iskandar $\mathrm{dkk}^{16}$, menyadari akan pentingnya tetap menjaga perekonomian masyarakat agar tetap stabil di saat pandemi. Oleh karena itu, UPZ atau unit pengelola zakat, sebagai salah satu cabang dari lembaga pengelolaan zakat yang ada di tingkat kecamatan diberdayakan peran dan fungsinya untuk meningkatkan perekonomian masyarakat

11 Widi Nopiarda, dan Wulan Yulia Sandani, Prosedur Pendistribusian Zakat pada BAZNAS Kabupaten Tanah Datar di Tengah Pandemi Covid19, ZAWA: Management of Zakat and Waqf Journal, 1 (1), 2021, 47-56

12 Afifuddin Kadir, dkk, Penggunaan Dana Zakat pada Korban Covid-19 Perspektif Maqashid Syariah, Al-Tafaqquh: Journal of Islamic Law, 1 (2), 2020, 107-116

${ }^{13}$ Uswatun Hasanah, Analisis Potensi Penerimaan Zakat melalui E-Commerce pada Masa Pandemi Covid-19, JISFIM: Journal of Islamic Social Finance Management, 2 (1), 2021, 122-134

${ }^{14}$ Fitra Rizal dan Haniatul Mukaromah, Filantropi Islam Solusi Atas Masalah Kemiskinan Akibat Pandemi Covid-19, Al Manhaj: Jurnal Hukum dan Pranata Sosial Islam, 3 (1) 2021, 35-66

15 Gebrina Rizki Amanda, dkk, Pendayagunaan Zakat pada Masa Pandemi Covid-19, Jurnal Imiah Ekonomi Islam (JIEI), 7 (1), 2021, 216-222

${ }_{16}$ Azwar Iskandar, Bayu Taufiq Possumah, dan Khaerul Aqbar, Peran Ekonomi dan Keuangan Sosial Islam Saat Pandemi Covid-19, SALAM: Jurnal Sosial \& Budaya Syar'i, 7 (7), 2020, 625-638 
sekitar. Yang menjadi sasaran program perekonomian ini ialah keluarga, hanya saja program ini kurang maksimal karena kurangnya sinergitas lembaga pengelola dengan lembaga lain yang lebih besar. Sementara, Hasanah ${ }^{17}$ tidak ikut fokus menyoroti pemanfaatan dana zakat, melainkan di bagian potensi pengumpulan harta zakat saat pandemi. Studi ini menemukan bahwa meski pandemi telah menghantam perekonomian, akan tetapi budaya berderma yang dilakukan masyarakat masih tinggi. Hal ini dapat dibuktikan melalui tingginya penerimaan dana zakat melalui platform e-commerce seperti Bukalapak, Lazada, Shoppee, Tokopedia, Blibli, JD.id, Elevania, dan Mataharimall.com.

\section{Kajian Pustaka}

\section{Fundraising}

Fundraising dapat berarti penggalangan dana. Fundraising dapat diartikan sebagai kegiatan menghimpun atau menggalang dana zakat, infaq, dan shodaqoh serta sumber lainnya dari masyarakat (baik individu, kelompok, organisasi, dan perusahaan), yang akan disalurkan dan didayagunakan untuk mustahik. ${ }^{18}$ Fundraising merupakan kegiatan yang sangat penting bagi lembaga atau organisasi sosial dalam upaya mendukung jalannya program dan menjalankan roda organisasi sosial tersebut dapat mencapai maksud dan tujuan yang telah digariskan. ${ }^{19}$ Strategi fundraising adalah rencana yang cermat untuk menggalang atau menggali dana dalam suatu kegiatan. Dan untuk kesuksesan dari penggalangan tersebut maka diperlukan yang namanya strategi, sehingga proses penggalangan tersebut dapat berjalan lebih terarah dan maksimal

\footnotetext{
${ }^{17}$ Uswatun Hasanah, Analisis Potensi Penerimaan Zakat melalui E-Commerce pada Masa Pandemi Covid-19, JISFIM: Journal of Islamic Social Finance Management, 2 (1), 2021, 122-134

18 Hafidudhin, Didin. Membangun Peradaban Zakat. (Jakarta: IMZ, 2006), 47.
}

dalam pelaksanaannya. Tetapi fundraising bukan mengenai meminta, tetapi lebih banyak mengenai menjual. Dan untuk pelaksanaannya memerlukan yang namanya strategi fundraising.

\section{Lembaga Filantropi Islam}

Setelah reformasi yang terjadi di tahun 1998, seiring dengan semakin besarnya kiprah lembaga-lembaga pengelolaan zakat, khususnya yang non-pemerintahan, pemerintah juga semakin menyadari bahwa sudah saatnya dibuat institusi dan regulasi zakat di Indonesia. Pada awal Agustus 1999, Menteri Agama A. Malik Fajar, membacakan RUU tentang Pengelolaan Zakat di depan sidang paripurna DPR-RI, hingga akhirnya pada tanggal 23 September 1999 Presiden B.J Habibie mengesahkan UU No. 38/1999 RUU tentang Pengelolaan Zakat. Dari situlah tercipta di antaranya tujuan dan manajemen pengelolaan (pengumpulan dan pendayagunaan zakat); dibentuknya lembaga pengelola zakat non pemerintah; diakuinya eksistensi lembaga pengelola non pemerintah; dapat dibentuknya Unit Pengumpul Zakat (UPZ) baik di dalam maupun luar negeri sebagai perpanjangan tangan BAZ dalam mengumpulkan zakat; zakat dapat dijadikan pengurang pajak; serta perlunya pengawasan terhadap kinerja badan amil zakat. ${ }^{20}$

Potensi zakat yang termasuk dalam rukun Islam dinilai oleh pemertintah dapat mengentaskan masalah kemiskinan. Dengan itu pemerintah mengamandemenkan Undang-Undang nomor 38 tahun 1999 tentang pengelolaan zakat menjadi Undang-Undang Nomor 23 tahun 2011 untuk memperbaiki UndangUndang nomor 38 tahun 1999 yang dianggap belum dapat memenuhi

19 Sani, M Anwar. Jurus Menghimpun Fulus: Manajemen Zakat Berbasis Masjid. (Jakarta: Gramedia Pustaka Utama, 2010), 25.

${ }^{20}$ Mintarti, Nana dkk. Zakat dan Pembangunan: Era Baru Zakat Menuju Kesejahteraan Umat. (Jakarta: Indonesia Magnifinence of Zakat, 2009), 7. 
kebutuhan hukum saat ini. UndangUndang nomor 23 tahun 2011 dimaksudkan untuk memastikan keteraturan dan akuntabilitas dalam perencanaan, pengumpulan, pendistribusian, dan pendayaan zakat. Akan tetapi dalam implementasinya Undang-Undang nomor 23 tahun 2011 mengalami banyak kontroversi karena dianggap mempersulit masyarakat dalam mengumpulkan zakat dan menyalurkan kembali kepada masyarakat. ${ }^{21}$

Setelah sekian waktu berjalan dan pengelolaan tentang organisasi pengelolaan zakat terus saja diperbaharui. Hingga salah satu yang terbaru pengelolaan zakat diatur dalam PP No. 14 Tahun 2014 yang menjelaskan tentang keberadaan OPZ pada setiap struktur BAZNAS, yaitu dari pusat hingga Kabupaten dan Kota.

Organisasi Pengelolaan zakat dibagi menjadi dua, yaitu: Pertama, Badan Amil Zakat (BAZ), yang merupakan OPZ yang dibentuk oleh pemerintah. Hubungan kerja BAZ disetiap tingkatan bersifat kordinatif, konsulatif, dan informatif. Pengurus BAZ terdiri dari unsur pemerintah dan masyarakat yang memiliki persyaratan tertentu. BAZ terdiri dari unsur pertimbangan, pengawas, dan pelaksana.

Kedua, Lembaga Amil Zakat (LAZ), yaitu lembaga yang dibentuk oleh masyarakat guna untuk membantu BAZNAS dalam pelaksaan pengumpulan, pendistribusian, dan pendayagunaan zakat, dengan catatan telah mendapat izin dari pejabat Kementerian Agama.

Dalam melaksanakan tugasnya, BAZ, LAZ dan UPZ memiliki tugas dan wewenang yang berbeda, dalam pasal 7 ayat 1 Undang-Undang No 23 Tahun 2011 menjelaskan tentang tugas dari BAZNAS yaitu perencanaan, pelaksanaan, pengendalian, dan pelaporan atas

${ }^{21}$ Rosyidah, Trie Anis dkk, Implementasi UndangUndanng Nomor 23 Tahun 2011 terhadap Legalitas Pengelolaan Zakat Oleh Lembaga Amil Zakat, pengumpulan, pendistribusian dan pendayagunaaan zakat. Sedangkan LAZ memiliki tugas membantu BAZNAS dalam pelaksanaan, pengumpulan, pendistribusian, dan pendayagunaan zakat. Hal tersebut diatur dalam pasal 17 UndangUndang No 23 Tahun 2011. Dan UPZ memiliki tugas membantu BAZNAS hanya dalam pengumpulan zakat yang diatur dalam pasal 1 ayat 9 yang selanjutnya dijelaskan dalam pasal 16 ayat 1 UndangUndang No 23 Tahun 2011.

Untuk pelaporan pertanggungjawaban atas pelaksanaan, pengumpulan, pendistribusian, dan pendayagunaan zakat maka BAZNAS berkewajiban melaporkan pertanggung jawaban kepada BAZNAS ditingkat lebih tinggi dan pemerintah daerah di masing-masing tingkatan wilayah, selanjutnya BAZNAS di tingkat Nasional melaporkan pertanggung jawabannya kepada Menteri. Adapun LAZ bekewajiban melaporkan pertanggung jawabnnya kepada BAZNAS dan pemerintah daerah masing-masing ditingkatan wilayah, yang mana hal ini diatur dalam pasal 29 Undang-Undang No 23 Tahun 2011. Sehingga dari aturan tersebut pemerintah berupaya untuk mensentralisasi Organisasi Pengelolaan Zakat dengan memposisikan BAZNAS lebih tinggi dari pada LAZ.

\section{Metode Penelitian}

Penelitian yang penulis lakukan ini merupakan penelitian pengembangan yang memperluas dan menjelaskan lebih dalam lagi tentang pengetahuan yang telah ada sebelumnya. Penelitian ini juga dilakukan dengan menggunakan jenis kualitatif yang dilakukan dengan pencarian fakta dan data secara langsung di lapangan dan dideskripsikan dalam bentu kata-kata, serta

Jurnal Ilmiah Mahasiswa FEB Universitas Brawijaya, 1 (1), 2016 
bahasa $^{22}$. Objek dalam penelitian ini di lembaga amil zakat LAZISNU Kota Semarang. Data diambil menggunakan teknik observasi, wawancara mendalam serta dokumentasi. Observasi dilakukan dengan melibatkan diri secara langsung di tempat penelitian, sementara wawancara mendalam dilakukan pada manajer fundraising lembaga pengelola zakat, serta bagian media dari lembaga pengelola zakat. Sedangkan, dokumen-dokumen didapatkan dari catatan rapat, laporan penghimpunan dana, berita online atau cetak, dan naskah lain yang memiliki kaitan dengan kajian. Selanjutnya, analisis dilakukan dengan cara reduksi data, penyajian data, penarikan kesimpulan dan verifikasi $^{23}$.

\section{Hasil dan Pembahasan}

Sebelum pandemi pelaksanaan strategi fundraising, NU CARE LAZISNU Kota Semarang menggunakan metode fundraising langsung dan fundraising tidak langsung. Dalam strategi fundraising sebelum masa pandemi Divisi Penghimpunan NU CARE-LAZISNU Kota Semarang lebih banyak menggunakan metode langsung, yaitu bertemu dengan para muzakki dan melaksanakan pembayaran zakat, infaq, atau shodaqoh secara bertatap muka secara langsung. Dalam strategi ini layanan kegiatan yang dilakukan dalam fundraising yaitu:

Pertama, Layanan Membayar Zakat Di kantor Terdekat. Dalam hal ini para muzakki datang secara langsung ke kantor NU CARE-LAZISNU Kota Semarang untuk membayar zakat, infaq, atau shodaqoh. Alamat kantor NU CARELAZISNU Kota Semarang yaitu di Jalan Puspogiwang 1 No.47 Kota Semarang.

Kedua, Membuka Stand Pembayaran ZIS Di Acara Keaagamaan NU. Dalam hal ini pengurus NU CARA-LAZISNU Kota

\footnotetext{
${ }^{22}$ Lexy, J. Moloeng, Metode Penelitian Kualitatif. (Bandung: Remaja Rosdakarya, 2009), 3.
}

Semarang mendatangi tempat-tempat yang sedang diadakan acara Nahdlatul Ulama (NU). Ditempat tersebut tim divisi penghimpunan NU CARE-LAZISNU Koa Semarang akan membuka stand pembayaran zakat, infaq, atau shodaqoh ditempat acara kegiatan.

Ketiga, Penyebaran Pamflet Informasi. Pada strategi ini NU CARELAZISNU Kota Semarang bermaksud mempromosikan diri ke masyarakat, agar mayarakat lebih paham tentang adanya lembaga amil zakat NU. Peletakan pamflet tersebut biasanya ada di masjid-masjid yang ada di Kota Semarang. Dalam pamflet tersebut yang berisi tentang profil lembaga serta program-program NU CARE-LAZISNU Kota Semarang.

Keempat, Penyebaran Kotak Koin Infaq. Pada program strategi ini, divisi fundraising NU CARE-LAZISNU Kota Semarang akan melakukan penyebaran dan peletakan kotak koin dari NU CARELAZISNU di toko-toko sumber dana NU Kota Semarang. Dengan adanya kotak koin di toko-toko tersebut, masyarakat yang sedang berbelanja sekaligus dapat juga ber infaq dan shodaqoh. Dengan harapan dapat memudahkan masyarakat dalam pembayaran infaq dan sdodaqoh.

Berbeda dengan strategi fundraising biasanya, saat pandemi proses penghimpunan dana NU CARE-LAZISNU Kota Semarang lebih inovatif dalam melakukan penghimpunan dana. Alasannya, karena dalam situasi pandemi ini semua kegiatan dan aktivitas masyarakat sedang dibatasi, mengikuti himbauan dari pemerintah untuk tidak berkerumun dan mematuhi protokol kesehatan yang telah ditetapkan. Dengan situasi yang ada di masa pandemi ini, maka strategi fundraising yang digunakan NU CARE-LAZISNU Kota Semarang yaitu:

Pertama, Layanan ZIS From Home. Program layanan ZIS from Home adalah

23 Sugiyono. Metode Penelitian Kualitatif. (Bandung: Alfabeta, 2018), 247-250. 
salah satu strategi fundraising NU CARELAZISNU Kota Semarang pada masa pandemi. Dalam program layanan ini divisi fundraising NU CARE-LAZISNU Kota Semarang akan mendatangi rumah-rumah para muzakki yang akan membayar zakat, infaq, atau shodaqoh. Dengan begitu para muzakki cukup dirumah saja jika akan membayarkan zakat, infaq, atau shodaqoh.

Sebagai pencegahan meluasnya virus corona pada masa pandemi Covid-19, pemerintah menginstruksikan kepada masyarakat untuk melakukan gerakan physical dan social distancing. Maka dari itu NU CARE-LAZISNU Kota Semarang membuat layanan ZIS From Home dan pembayaran zakat, infaq, dan shodaqoh secara online. Sebagaimana yang diutarakan oleh Manajer Fundraising NU CARE LAZISNU Kota Semarang Zidan Esriyanto:

"mengikuti anjuran pemerintah yang mengharuskan masyarakat untuk dirumah saja, maka NU CARELAZISNU Kota Semarang menciptkan layanan ZIS From Home sebagai inovasi dalam proses penghimpunan. Bukan hanya itu, NU CARE LAZISNU Kota Semarang juga menciptakan layanan konsultasi dan pembayaran zakat secara online, hal ini dilakukan untuk meningkatkan jumlah penghimpunan dana yang didapatkan oleh NU CARELAZISNU Kota Semarang yang pada awal pandemi mengalami penurunan jumlah penghimpunan dana"

Kedua, Layanan Transfer ATM dan Internet Banking. Dalam layanan ini para muzakki hanya tinggal berkomunikasi dengan pihak NU CARE-LAZISNU Kota Semarang jika akan melakukan pembayaran zakat, infaq, atau shodaqoh. Nomor kontak yang bisa dihubungi yaitu 0822-2144-0238 / 0857-9982-5795, setelah itu muzakki dapat melakukan transaksi melalui transfer ATM. Terdapat empat nomor rekening yang digunakan untuk menyalurkan zakat, keempat rekening tersebut juga atas nama LAZISNU Kota Semarang. Pertama yaitu nomor rekening dari Bank BRI dengan nomor 105801005132535 , kedua dari Bank BTN Syariah dengan nomor rekening 71420874 36, ketiga yaitu dari Bank Jateng dengan nomor rekening 30560646 80, keempat yaitu KSPPS BMT NUS dengan nomor rekening 0011623053.

Ketiga, Pembayaran ZIS dengan Scanner Barcode / QR kode. Tujuan dibuatnya QR code adalah untuk mempermudah muzakki dalam memperoleh informasi dan pembayaran infaq di NU CARE-LAZISNU Kota Semarang. NMID : ID2019008024505 adalah nomer id yang dimilki NU CARE LAZISNU dalam barkodenya. Barcode tersebut dapat digunakan dan diakses oleh semua aplikasi keuangan digital. Jadi dengan QR code terrsebut dapat mempermudah muzakki dalam pembayaran zakat infaq, atau shodaqoh pada masa pandemi Covid-19.

Keempat, Kerjasama Program dengan Instansi atau Perusahaan Lainnya. Pada situasi pandemi Covid-19 ini banyak sekali instansi atau perusahaan yang secara besarbesaran melakukan bantuan baik secara tunai maupun non tunai kepada masyarakat. Pada kesempatan ini NU CARE-LAZISNU Kota Semarang bekerja sama dengan Perusahaan ojek online Gojek Indonesia. Dalam kerjasama tersebut melalui CSR Gojek Indonesia melaksanakan program berbagi sembako Peduli Dhuafa untuk membantu ekonomi masyarakat yang membutuhkan dan dalam rangka mencegah kerentanan masyarakat dalam menghadapi situasi pandemi Covid19. Dalam hal ini penthasharufan di wilayah Kota Semarang dilakukan oleh NU CARE-LAZISNU Kota Semarang.

Pada masa pandemi Covid-19 banyak sekali program kerja NU CARELAZISNU Kota Semarang yang sebelumnya sudah dirancang dan 
dipersiapkan jauh-jauh hari menjadi tidak bisa dilaksakanakan. Namun hal itu tidak mengurangi produktifitas dari NU CARE LAZISNU Kota Semarang untuk tetap aktif sebagai lembaga amil zakat yang aktif dalam pengelolaan zakat, infaq, dan shodaqoh. Upaya yang dilakukan oleh NU CARE-LAZISNU Kota Semarang dalam meningkatkan jumlah pembayaran zakat, infaq, dan shodaqoh adalah melakukan kerja sama program dengan Instansi dan Perusahaan lain. Sebagaimana yang diutarakan oleh Esriyanto:

"Masa pandemi Covid-19 telah banyak menghentikan programprogram yang biasa dilaksanakan oleh NU CARE-LAZISNU Kota Semarang, untuk kembali menjalankan program-program baru yang efektif, tepat, dan cepat NU CARE LAZISNU Kota Semarang menggandeng beberapa Instansi dan Perusahaan untuk mensukseskan program-program tersebut, terkhusus dalam situasi pandemi ini yang paling diutamakan yaitu program bantuan sosial bagi masyarakat yang terkena dampak pandemi Covid-19" (Wawancara dengan Zidan Esriyanto, 1 Desember 2020)

Faktor keberhasilan peningkatan jumlah penghimpunan dana paling efektif yaitu dari upaya kerja sama NU CARELAZISNU Kota Semarang dengan Instansi dan Perusahaan lain. Salah satu contohnya yaitu ketika dari Pabrik SANGO menyumbangkan infaq $\mathrm{Rp} \quad 10.000 .000$ pada awal bulan April. Hal tersebutlah yang lantas mengangkat jumlah penghimpunan dana NU CARE LAZISNU hingga mencapai jumlah total $\mathrm{Rp}$ 45.688.158 pada bulan April.

Peningkatan jumlah penghimpunan dana NU CARE LAZISNU Kota Semarang berlanjut pada bulan Mei 2020. Jumlah penghimpunan tertinggi pada bulan Mei juga dari upaya kerja sama dengan Perusahaan dan Institusi. Pada bulan Mei
PR SUKUN menyumbang infaq sebesar Rp 70.000.000 . Hal tersebut juga yang membuat jumlah penghimpunan NU CARE-LAZISNU Kota Semarang meningkat. Hingga jumlah total penghimpunan pada bulan Mei 2020 mencapai Rp 117.468.965

Maksimalisasi Fungsi Fundraising di NU CARE LAZISNU Kota Semarang

Fundraising yang dilakukan lembaga pengelola zakat tidak jauh berbeda dengan saat sebelum pandemi, hanya saja pembatasan waktu bekerja dan bertemu orang lain saat pandemi menjadikan kendala. Sehingga, upaya yang dilakukan dengan memperkuat fundraising melalui online

NU CARE-LAZISNU Kota Semarang dalam upaya meningkatkan kualitas, kuantitas, dan memperkenalkan kepada calom muzakki untuk pengembangan zakat, infaq, dan shodaqoh agar dapat diperdayakan secara optimal menggunakan metode fundraising. NU CARE-LAZISNU Kota Semarang mengacu pada UndangUndang No. 23 Tahun 2011 tentang pengelolaan zakat yang menghendaki adanya sosialisasi kepada masyarakat luas. Dengan menggunakan strategi yang efektif dan efisien NU CARE-LAZISNU Kota Semarang dalam mensosialisasikan lembaganya mempunyai beberapa strategi, dengan strategi tersebut diharapkan dapat merubah paradigma pengelolaan zakat, infaq, dan shodaqoh menjadi lebih terarah dan lebih baik.

Tujuan tertinggi dari proses fundraising adalah kepuasan muzakki dalam menunaikan zakat, infaq, dan shodaqoh. Sebab jika para muzakki puas, mereka akan kembali mendonasikan maupun menunaikan zakat, infaq, dan shodaqohnya di lembaga semula. Kebalikannya jika muzakki tidak puas, maka ia akan menghentikan donasinya (tidak mengulang lagi) di lembaga tersebut. Maka secara otomatis kegiatan 
fundraising juga bertujuan untuk memberi rasa aman dan kepuasan kepada muzakki.

Situasi pandemi covid-19 menuntut banyak perubahan dalam proses fundraising zakat, infaq, dan shodaqoh. Di tengah pandemi ini NU CARE-LAZISNU Kota Semarang berupaya semaksimal mungkin untuk tetap menjadi pilihan dan kepercayaan masyarakat dalam menunaikan pembayaran zakat, infaq, dan shodaqoh. Maka dari itu NU CARELAZISNU Kota Semarang menciptakan inovasi-inovasi yang dapat memudahkan dan tetap memberi rasa aman kepada masyarakat yang akan menunaikan zakat, infaq, dan shodaqohnya pada masa pandemi Covid-19.

\section{Fundraising Sebagai Expansion dan Development}

Fundraising di masa pandemi seperti sekarang ini memiliki dua sisi yang saling berakitan. Sisi pertama tidak mudah, karena semua orang terkena dampak ekonomi dari pandemi. Sedangkan sisi yang lain fundraising penting, untuk dapat membantu orang terdampak paling parah.

Meningkatkan jumlah donatur di saat pandemi merupakan usaha yang tidak mudah. Oleh karena itu, peningkatan jumlah donatur dilakukan secara kualitatif, dengan merawat donatur yang telah ada melalui layanan terbaik

"Dalam prinsip fundraising NU CARE-LAZISNU Kota Semarang selalu mengedepankan pelayanan yang maksimal kepada para donatur, baik dari awal proses perencanaan program, pelaksanaan program, dan evaluasi program selalu mengedepankan kepuasan dan kenyamanan guna terbentuknya kepercayaan masyarakat kepada NU CARE-LAZISNU Kota Semarang" (wawancara dengan Zidan Esriyanto, Manajer Fundraising, pada 1 Desember 2020)

Proses penghimpunan dana yang dilakukan oleh NU CARE-LAZISNU Kota
Semarang selalu mengedepankan kenyamanan, kepuasaan dan rasa aman donatur. Dalam pengelolaannya NU CARE LAZISNU Kota Semarang selalu melakukan hubungan baik dan pendekatan kepada beberapa pihak, seperti kepada para Kyai Nahdlatul Ulama, para pengusaha, institusi, perusahaan, dan lain-lain.

Melalui prinsip fundraising adalah harus meminta, NU CARE-LAZISNU Kota Semarang melaksanakannya melalui pembuatan program-program penghimpunan dana. Dalam contohnya yaitu melalui penyampaian pesan kepada para muzakki yang biasanya telah menyalurkan zakat, infaq, dan shodaqohnya di NU CARE-LAZISNU Kota Semarang, sehingga dari pihak pegawai NU CARE LAZISNU Kota Semarang sudah memiliki kontak dan alamat dari para muzakki. Hal tersebut juga berguna untuk pelaksanaan prinsip fundraising sebagai adalah tanggung jawab dan melapor, sebagai bentuk penyampaian laporan pengelolaan dana yeng telah diberikan oleh para muzakki/donatur kepada NU CARE-LAZISNU Kota Semarang.

Selain penerapan prinsip fundraising sebagai tanggung jawab dan pelaporan, NU CARE-LAZISNU Kota Semaranng juga sudah melaksanakan dengan sangat baik dari prinsip fundraising adalah mengucapkan terima kasih. Ucapan terima kasih bisa diucapkan secara langsung maupun tidak langsung. Dalam contohnya apabila ada donasi infaq atau shodaqoh atas nama dari Perusahaan dan Intitusi, selain ucapan terima kasih secara langsung, NU CARE LAZISNU Kota Semarang juga membuatkan desain foto ucapan terima kasih untuk Perusahaan atau Intstitusi tersebut, setelahnya desain tersebut di unggah di media sosial milik NU CARE LAZISNU Kota Semarang.

Selain itu, NU CARE LAZISNU Kota Semarang juga menerapkan prinsip fundraising adalah menjual. Contohnya 
yaitu melalui pembuatan progran paket sembako. Dalam masa pandemi ini. NU CARE membuat program paket sembako seharga $\mathrm{Rp} 100.000$ yang berisi berbagai kebutuhan pokok. Setelahnya program tersebut ditawarkan dan dijual kepada masyarakat untuk mempengaruhi agar ikut membantu sesamanya dengan memberikan dana, yang setelahnya paket sembako tersebut dikembalikan kepada masyarakat untuk membantu mereka yang terkena dampak dari pandemi Covid-19.

Berdasarkan teori menghimpun dana dan dilakukannya prinsip-prinsip fundraising dalam melaksanakan strategi penghimpunan dana untuk mencapai tujuan meningkatkan jumlah penghimpunan dana, NU CARELAZISNU Kota Semarang telah berupaya dengan maksimal dalam menjalankannya. Dengan maksimalisasi tersebut diharapkan jumlah penghimpunan dana yang didapatkan oleh NU CARE LAZISNU Kota Semarang bisa meningkat meski dalam masa pandemi Cocid-19.

\section{Kesimpulan}

Berdasarkan pembahasan di atas, dapat disimpulkan bahwasannya fundraising yang dilakukan lembaga pengelola zakat LAZISNU Kota Semarang tidak jauh berbeda dengan saat sebelum pandemi, hanya saja pembatasan waktu bekerja dan bertemu orang lain saat pandemi menjadikan kendala. Sehingga, upaya yang dilakukan dengan memperkuat fundraising melalui online. Fundraising di masa pandemi seperti sekarang ini memiliki dua sisi yang saling berakitan. Sisi pertama tidak mudah, karena semua orang terkena dampak ekonomi dari pandemi. Sedangkan sisi yang lain fundraising penting, untuk dapat membantu orang terdampak paling parah. Meningkatkan jumlah donatur di saat pandemi merupakan usaha yang tidak mudah. Oleh karena itu, peningkatan jumlah donatur dilakukan secara kualitatif, dengan merawat donatur yang telah ada melalui layanan terbaik.

\section{Daftar Pustaka}

Abidah, Atik, Analisis Strategi Fundraising terhadap Peningkatan Pengelolaan ZIS pada Lembaga Amil Zakat Kabupaten Ponorogo, Kodifikasia, 10 (1), 2016, 163-189

Amanda, Gebrina Rizki, dkk, Pendayagunaan Zakat pada Masa Pandemi Covid-19, Jurnal Imiah Ekonomi Islam (JIEI), 7 (1), 2021, 216-222

Darmawan, Awang, dan Rina Desiana, Zakat dan Pemerataan Ekonomi di Masa Pandemi Covid-19, Al Azhar: Journal of Islamic Economics, 3 (1), 2021, 12-21

Hafidudhin, Didin. Membangun Peradaban Zakat. (Jakarta: IMZ, 2006).

Harisah, dkk, Peran Zakat dalam Pemulihan Ekonomi saat Pandemi Covid-19, Syar'i, 4 (1), 2021, 54-66

Hasanah, Uswatun, Analisis Potensi Penerimaan Zakat melalui ECommerce pada Masa Pandemi Covid-19, JISFIM: Journal of Islamic Social Finance Management, 2 (1), 2021, 122-134

Iskandar, Azwar, Bayu Taufiq Possumah, dan Khaerul Aqbar, Peran Ekonomi dan Keuangan Sosial Islam Saat Pandemi Covid-19, SALAM: Jurnal Sosial \& Budaya Syar'i, 7 (7), 2020, 625-638

Kadir, Afifuddin, dkk, Penggunaan Dana Zakat pada Korban Covid-19 Perspektif Maqashid Syariah, AlTafaqquh: Journal of Islamic Law, 1 (2), 2020, 107-116

Khoirudin, Ahmad, Analisis Dampak Pandemi Covid-19 terhadap Perekonomian Provinsi Sumatra Selatan, Jurnal Iqtishaduna: Economic Doctrine, 6 (1) 2021, 532541 
Kinanti, Risma Ayu, dkk, Optimalisasi Fundraising Zakat pada Kerjasama Institusional Indonesia Melalui ECommerce Pasca Pandemi Covid-19, Filantropi: Jurnal Manajemen Zakat dan Wakaf, 2 (1), 2021, 20-37

Kurniasih, Erni Panca, Dampak Pandemi Covid 19 terhadap Penurunan Kesejahteraan Masyarakat Kota Pontianak, Prosiding Seminar Akademik Tahunan Ilmu Ekonomi dan Studi Pembangunan, 2020, 1-13

Nopiarda, Widi, dan Wulan Yulia Sandani, Prosedur Pendistribusian Zakat pada BAZNAS Kabupaten Tanah Datar di Tengah Pandemi Covid-19, ZAWA: Management of Zakat and Waqf Journal, 1 (1), 2021, 47-56

Nuryadi dan Nisa Lestari, Dampak Pandemi Covid-19 terhadap Tenaga Kerja Desa Cibanteng Kecamatan Ciampea Kabupaten Bogor, Yustisi: Jurnal Hukum \& Hukum Islam, 6 (1) 2019, 29-38

Mintarti, Nana dkk. Zakat dan Pembangunan: Era Baru Zakat Menuju Kesejahteraan Umat. (Jakarta: Indonesia Magnifinence of Zakat, 2009).

Moloeng, Lexy, J., Metode Penelitian Kualitatif. (Bandung: Remaja Rosdakarya, 2009).

Rizal, Fitra dan Haniatul Mukaromah, Filantropi Islam Solusi Atas Masalah Kemiskinan Akibat Pandemi Covid19, Al Manhaj: Jurnal Hukum dan Pranata Sosial Islam, 3 (1) 2021, 35 66

Rosadi, Syukri, Peran UPZ (Unit Pengumpul Zakat) Ujungbatu dalam Meningkatkan Ekonomi Masyarakat saat Pandemi Covid-19, HUKUMAH: Jurnal Hukum Islam, 3 (2), 2020, 141-151

Rosyidah, Trie Anis dkk, Implementasi Undang-Undanng Nomor 23 Tahun 2011 terhadap Legalitas Pengelolaan Zakat Oleh Lembaga Amil Zakat,
Jurnal Ilmiah Mahasiswa FEB Universitas Brawijaya, 1 (1), 2016 Sakinah, Nur, dan AG Maulana, Peran Distribusi Harta (Zakat) sebagai Solusi Ekonomi di Saat Pandemi Covid-19 pada BAZNAS Kabupaten Kepulauan Meranti, Kutubkhanah: Jurnal Penelitian Sosial Keagamaan, 20 (1), 2020, 65-79

Sani, M Anwar. Jurus Menghimpun Fulus: Manajemen Zakat Berbasis Masjid. (Jakarta: Gramedia Pustaka Utama, 2010).

Sugiyono. Metode Penelitian Kualitatif. (Bandung: Alfabeta, 2018)

Tamim, Imron Hadi, Filantropi dan Pembangunan, Jurnal Community Development, 1 (1), 2016, 121-136

Tapung, Marianus Mantovanny, dkk, Bantuan Sosial dan Pendidikan Kesehatan bagi Masyarakat Pesisir yang Terdampak Sosial-Ekonomi selama Patogenesis Covid-19 di Manggarai, Transformasi: Jurnal Pengabdian Masyarakat, 16 (1), 2020: $12-26$ 